\title{
Synchronized Phasor Measurements of a Power System Event in Eastern Denmark
}

\author{
Rasmussen, Joana; Jørgensen, Preben
}

Published in:

IEEE Transactions on Power Systems

Link to article, DOI:

10.1109/TPWRS.2005.860947

Publication date:

2006

Document Version

Publisher's PDF, also known as Version of record

Link back to DTU Orbit

Citation (APA):

Rasmussen, J., \& Jørgensen, P. (2006). Synchronized Phasor Measurements of a Power System Event in Eastern Denmark. IEEE Transactions on Power Systems, 21(1), 278-284.

https://doi.org/10.1109/TPWRS.2005.860947

\section{General rights}

Copyright and moral rights for the publications made accessible in the public portal are retained by the authors and/or other copyright owners and it is a condition of accessing publications that users recognise and abide by the legal requirements associated with these rights.

- Users may download and print one copy of any publication from the public portal for the purpose of private study or research.

- You may not further distribute the material or use it for any profit-making activity or commercial gain

- You may freely distribute the URL identifying the publication in the public portal

If you believe that this document breaches copyright please contact us providing details, and we will remove access to the work immediately and investigate your claim 


\title{
Synchronized Phasor Measurements of a Power System Event in Eastern Denmark
}

\author{
Joana Rasmussen and Preben Jørgensen, Senior Member, IEEE
}

\begin{abstract}
Two sets of synchronized phasor measurements $200 \mathrm{~km}$ apart have been performed during a planned outage of a double 400-kV tie-line between Eastern Denmark and Southern Sweden. The interconnection between Eastern Denmark and Southern Sweden is comprised of a double $400-\mathrm{kV}$ line and a double $132-\mathrm{kV}$ line. The outage of the $400-\mathrm{kV}$ tie-line weakened the Eastern Danish power system and excited power oscillations in the interconnected power systems. During this event prototype, phasor measurements units gave the opportunity of real-time monitoring of positive sequence voltage and current phasors using the satellite-based global positioning system. Comparisons between real-time recordings and results from dynamic simulations with Power System Simulator for Engineering are presented. The main features from the simulation analysis are successfully verified by means of the corresponding synchronized phasor measurements.
\end{abstract}

Index Terms-Power system measurements, power system monitoring, power system stability.

\section{INTRODUCTION}

$\mathbf{P}$ HASOR measurement units (PMUs) that rely on satellitebased global positioning system (GPS) clocks, give the opportunity of real-time monitoring of phasor measurements. Measurements from widely separated locations in the power system can be synchronized at a common time reference and collected at a central location. In that way, detailed information about the actual operational status of the power system can be preserved in a precise way. Synchronized phasor measurements can be used as an efficient tool both in warning of abnormal system conditions in due time and in analysis of critical events after severe disturbances in the power system.

Synchronized phasor measurements from a limited number of dispersed locations in the power grid can be used for enhanced monitoring of the power system, as well as for presentation of the critical dynamics in the power system [11]. The choice of representative locations for the PMUs is dependent upon the investigated dynamic phenomena, network size and characteristics, as well as communication and data transfer constraints [10].

Correct identification of oscillation modes using simulation of the Nordic power system requires exhaustive eigenvalue

Manuscript received June 10, 2004; revised August 1, 2005. This work was supported in part by Elkraft System Ltd. and in part by the Danish Academy of Technical Science. This paper is based on a contribution presented at the 2003 IEEE Bologna Power Tech, Bologna, Italy, June 23-26, 2003. Paper no. TPWRS-00316-2004.

J. Rasmussen is with the Technical University of Denmark, Lyngby DK-2800, Denmark (e-mail: jor@oersted.dtu.dk).

P. Jørgensen is with the Transmission Department, Elkraft System Ltd., 2650 Ballerup, Denmark (e-mail: prj@elkraft.dk).

Digital Object Identifier 10.1109/TPWRS.2005.860947 analysis. We were unfortunately not able to perform such simulation analysis, since the actual generation and load pattern in the Nordic power system was not sufficiently known. The exact computation of oscillation modes is dependent on extensive data on actual number of machines in operation as well as the impedance path of tie-lines and transmission corridors in the Nordic grid.

Instead, Nordic interarea oscillation modes are derived directly from phasor measurements captured during a tie-line switching between Eastern Denmark and Sweden. The recorded switching event excited well-damped power oscillations that had a moderate impact effect on the power system. The case illustrated in this paper was among the first Nordic applications of synchronized phasor measurements for power oscillation monitoring. Important system-wide oscillation frequencies are easily detected using positive sequence phasors at respective buses in Sweden and Eastern Denmark. In fact, this method is more convenient than modal analysis using a detailed model of a large interconnected system.

\section{Power System DeSCRIPTION}

The Nordic system shown in Fig. 1 is comprised of synchronized power systems in Norway, Finland, Eastern Denmark, and Sweden. The installed capacity of the entire Nordic system is about $90 \mathrm{GW}$, and the peak load is $60 \mathrm{GW}$. The total installed capacity in Eastern Denmark is $4360 \mathrm{MW}$, and the maximum load is about 2870 MW. The transmission grid in Eastern Denmark encompasses overhead lines and cables at the two highest voltage levels, i.e., transmission at 132 and $400 \mathrm{kV}$, and the interconnections with Southern Sweden and Germany. The link between Eastern Denmark and Sweden has a total transfer capacity of some $1600 \mathrm{MW}$, and it serves as an interconnection between two parts of the Nordic power system. Fig. 2 shows the Eastern Danish 400-kV grid together with the northeastern interconnection to Sweden and the southern interconnection to Germany. The link to Germany is a $400-\mathrm{kV}$ dc interconnection with a transmission capacity of $600 \mathrm{MW}$. The interconnection between Eastern Denmark and Southern Sweden consists of two $400-\mathrm{kV}$ circuits connected to the $400-\mathrm{kV}$ busbar in Söderåsen and two $132-\mathrm{kV}$ circuits connected to the $132-\mathrm{kV}$ busbar in Mörarp (see Fig. 3). Each 400-kV circuit consists of overhead circuits in Denmark and Sweden and three $400-\mathrm{kV}$ single-phase submarine cables and a seventh single-phase cable as spare.

Each 132-kV circuit consists of overhead circuits in Denmark and in Sweden and two three-phase submarine cables. There is a 400/132-kV transformer in Söderåsen and two 132-kV circuits between Söderåsen and Mörarp, each with a length of $8 \mathrm{~km}$. 


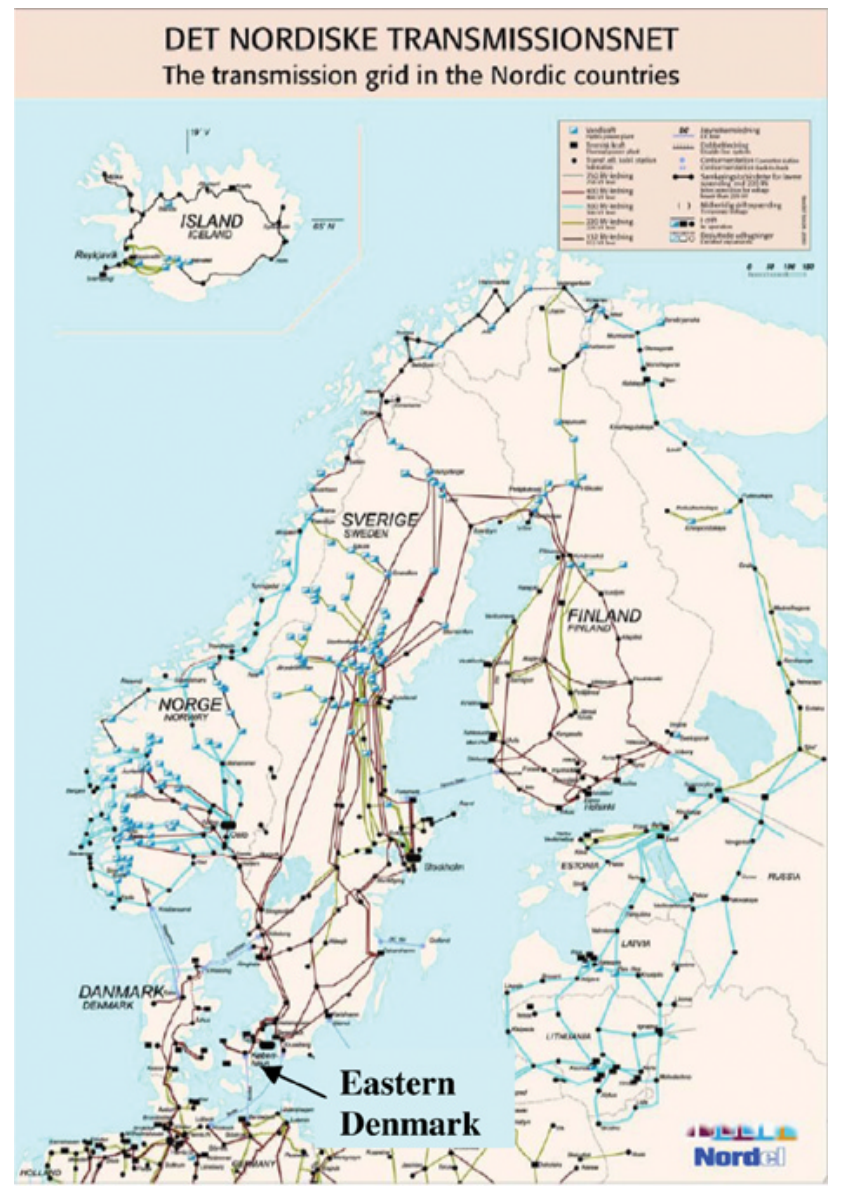

Fig. 1. Transmission grid of the Nordic countries.

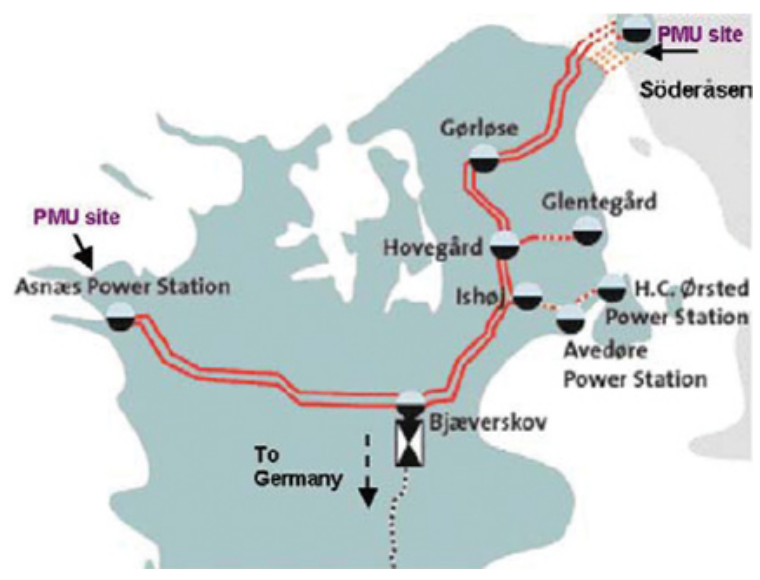

Fig. 2. $400-\mathrm{kV}$ transmission grid in Eastern Denmark. One PMU was placed at $\mathrm{ASV}$, and another PMU was placed $200 \mathrm{~km}$ away at SAN in Southern Sweden.

\section{A. Event Description}

The $400-\mathrm{kV}$ power system of Eastern Denmark with a simplified representation of the Swedish grid is represented in Fig. 3. The equivalent $400-\mathrm{kV}$ backbone network includes the double $400-\mathrm{kV}$ tie-line connection (shown in full lines) between substation Hovegård (HVE) in Denmark and Söderåsen (SAN) in Sweden. The $132-\mathrm{kV}$ tie-line given by dotted lines in Fig. 3 is terminated at Mörarp (MRP) in Sweden and Teglstrupgård substation (TEG) in Eastern Denmark.

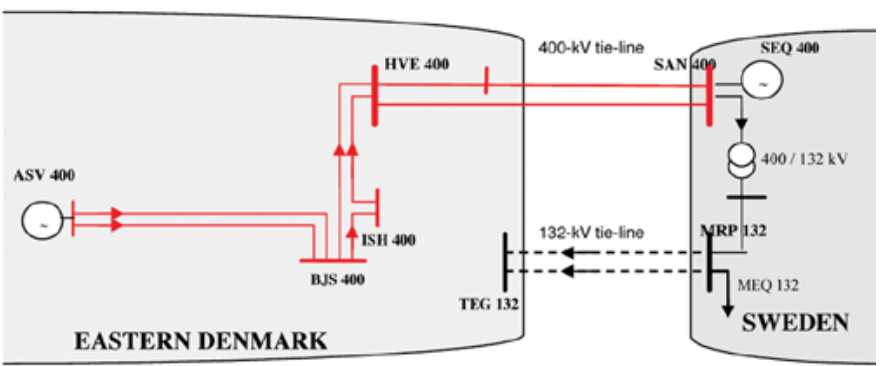

Fig. 3. Two-area model of interconnected power systems.

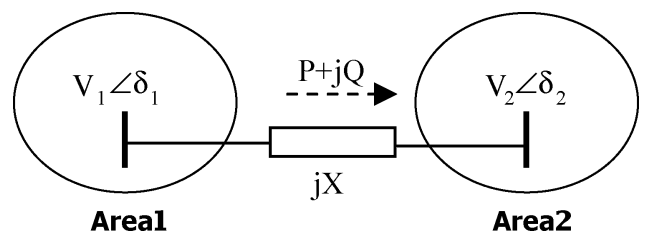

Fig. 4. Interarea power oscillations involving two areas.

The power system event studied is a planned switching of the 400-kV tie-lines between Söderåsen and Hovegård substations. The lines were deliberately disconnected due to connection of a new substation in the 400-kV transmission system. Due to technical constrains ${ }^{1}$ during the outage period the power transfer was deliberately limited to 100 MW (import or export to Sweden) compared to some $1600 \mathrm{MW}$ at normal conditions. Hence, the line switching appeared as an event that weakened the Eastern Danish power system.

The disconnection of the 400-kV tie-lines between Eastern Denmark and Sweden can be understood as an interruption of an important corridor in the interconnected system followed by fluctuating forces in the other transmission lines. Power oscillations occurred on the tie-lines connecting different groups of machines as a result of temporary unbalance between power input and output.

\section{Power Oscillations In InTERConNeCted Systems}

The power system in Fig. 4 shows a two-area model of major generation/load areas connected by a tie-line.

In general, the dynamics of power oscillations in large systems [1] is related to the power flow $P$ in a tie-line as follows:

$$
P=\frac{V_{1} \cdot V_{2}}{X} \sin \left(\delta_{1}-\delta_{2}\right)
$$

where $X$ is the line reactance, and $V_{1}, V_{2}, \delta_{1}$, and $\delta_{2}$ are the magnitudes and angles of the voltages at the line terminals.

Interarea power oscillations are dependent on the power system response to small disturbances such as change in scheduled generation or small increase in system load after the system has been perturbed from a steady-state condition [2]. The phenomenon of small signal stability is related to small changes of system quantities such as power and machine angles $(\Delta \delta)$. The free response of $n$-machine power system is derived

\footnotetext{
${ }^{1}$ A previous disturbance in April 1985 demonstrated that there was a considerable risk for undamped power oscillations when the export from Denmark to Sweden increased to $300 \mathrm{MW}$.
} 
from the linearized version of the well-known swing equation of motion of an ideal unregulated machine $i$ [16]

$$
\frac{d^{2}\left(\Delta \delta_{i j}\right)}{d t^{2}}+\frac{\omega_{R}}{2 H_{i}} \cdot \sum_{\substack{j=1 \\ j \neq i}}^{n} P_{s i j} \Delta \delta_{i j}=0 .
$$

According to (2), the power oscillations are dependent on the rated system frequency $\omega_{R}(\mathrm{rad})$, the inertia constant $H_{i}$ for machine $i$, and the synchronizing power coefficient $P_{s i j}$, which is related to the change in electrical power in machine $i$ due to angle change between machines $i$ and $j$, with all other machine angles held constant. In general, electromechanical oscillations in interconnected power systems are manifested by an exchange in mechanical kinetic energy between groups of generators as electric power flows through the transmission system. The small signal stability of large power systems is characterized by a number of complex eigenvalues for each oscillating mode. Each mode is associated with a single eigenfrequency and a damping factor. Successful damping of power oscillations indicates a stable system that is able to return to an acceptable steady-state situation after being exposed to a disturbance. A damping factor of $3 \%-5 \%$ is accepted as reasonable for damping of interarea modes [8].

In general, computation of eigenvalues in large power systems is a complex task, since it involves a systematic procedure for simultaneous solution of differential equations representing synchronous machines with associated prime movers, excitation systems, and power system stabilizers (PSS), extensive transmission networks, load dynamics, power electronic devices (such as HVDC links, SVC), etc. Analysis of interarea oscillations in large interconnected power systems requires comprehensive offline studies, such as eigenvalue analysis and dynamic simulations using a detailed model of the entire system, including a wide range of nonlinear devices. For example, the identification of Nordic system modes is to a great extent dependent upon the actual configuration of the interconnected power systems [14]. It means that detailed information about a number of machines in operation (system inertias), the impedance path of the tie-lines, and the transmission corridors (transmission stiffness between the inertias) is the key issue for determination of oscillation modes associated with a particular eigenfrequency and damping.

A more effective way to observe interarea oscillation modes and system damping is using phasor measurements from PMUs [7], [15]. The advantage of phasor measurements for tracking system dynamic phenomena is further discussed.

\section{MEASUREMENTS}

Two PMU prototypes, ABB RES 521 PMU $\beta$ version, were commissioned independently of each other at ASV and SAN in Southern Sweden in order to record frequency and positive sequence phasor quantities such as $400-\mathrm{kV}$ busbar voltages, currents in 400/132-kV transformers, and currents in outgoing $132-\mathrm{kV}$ lines at the respective locations, which are $200 \mathrm{~km}$ apart. The instantaneous values of the voltages and currents were sampled with a sampling rate of $36 \mathrm{kHz}$, aligned and downsampled in two steps to a sampling rate of $1 \mathrm{kHz}$. The

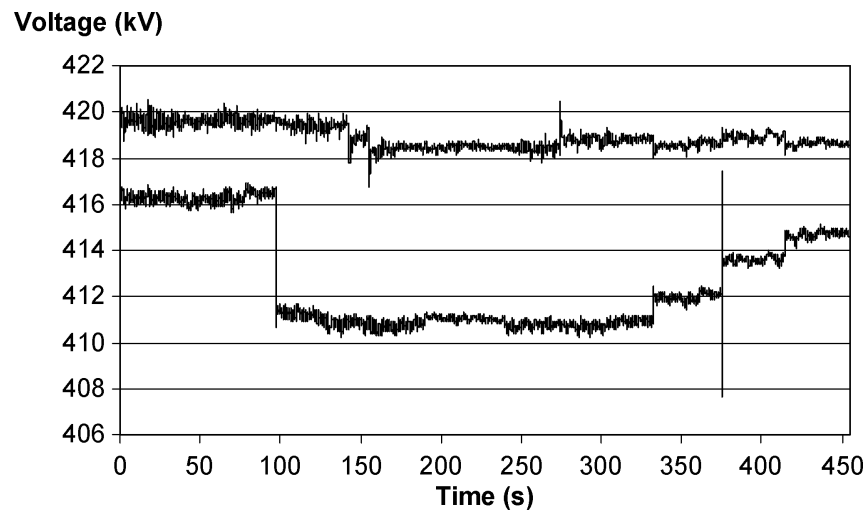

Fig. 5. Voltage magnitude measured as a function of time. The lower curve shows the voltage at SAN, while the upper curve shows the voltage at ASV.

synchronized phasors are calculated using these samples of the instantaneous values and reported every $20 \mathrm{~ms}$ using time transmissions from the GPS satellites [4], [7]. The recordings were stored on a PC near the PMUs. After normal operation was re-established, the data from the remote substations were aligned according to a common time reference [3].

The synchronized recordings at ASV and SAN were compared directly due to the fact that the voltage and current measurements are assigned the same time stamp and phase reference supplied by GPS clock. The accuracy of phasor measurements [12] is quoted to be $\pm 0.005 \mathrm{~Hz}$ for frequency accuracy and $\pm 0.1^{\circ}$ for angle accuracy. The measurement accuracy of phase angles is primarily caused by transducers at transmission level. In general, the precision of the synchronization is up to $1 \mu \mathrm{s}$, which introduces a negligible measurement error [5].

The voltage magnitude at SAN during the reconnection sequence is presented in Fig. 5 as the lower curve. The voltage decrease after $90 \mathrm{~s}$ was caused by the connection of a 150-MVAr reactor in SAN. The first 400-kV tie-line was energized from the Danish side, and the line reconnection to Sweden was completed at $330 \mathrm{~s}$. The second $400-\mathrm{kV}$ line inserted at SAN gave rise to a transient peak at $370 \mathrm{~s}$. Subsequently, the voltage builds up until the second line reconnection is completed at about 400 s. Fig. 5 also indicates the measured voltage at ASV, where the voltage variations are limited within $2 \mathrm{kV}$ due to the power plant voltage regulation.

The oscillations in relative phase angle (see Fig. 6) between SAN and ASV are observed before the first $400-\mathrm{kV}$ connection is established at $330 \mathrm{~s}$. A phase shift of about $1.3^{\circ}$ occurs after the reconnection of the first $400-\mathrm{kV}$ tie-line. After the second $400-\mathrm{kV}$ line is reconnected at about $400 \mathrm{~s}$, the voltage angle difference between SAN and ASV is further decreased to lower amplitude, and the oscillation is successfully damped.

Fig. 6 shows that the power system was weakened (but not severely stressed) during the recorded switching event. The small effect on the power system (small initial angles and moderate phase shift) is influenced by low tie-line transfer ${ }^{2}$ and total system load of about $65 \%$ of maximum load. The phase shift of $1.3^{\circ}$ recorded is within the phase angle accuracy, which, according to the PMU manufacturer, is quoted to be $0.1^{\circ}$. Thus, the presented recordings can be neither used as a benchmark

\footnotetext{
${ }^{2}$ It was deliberately controlled to $100 \mathrm{MW}$ in each direction.
} 


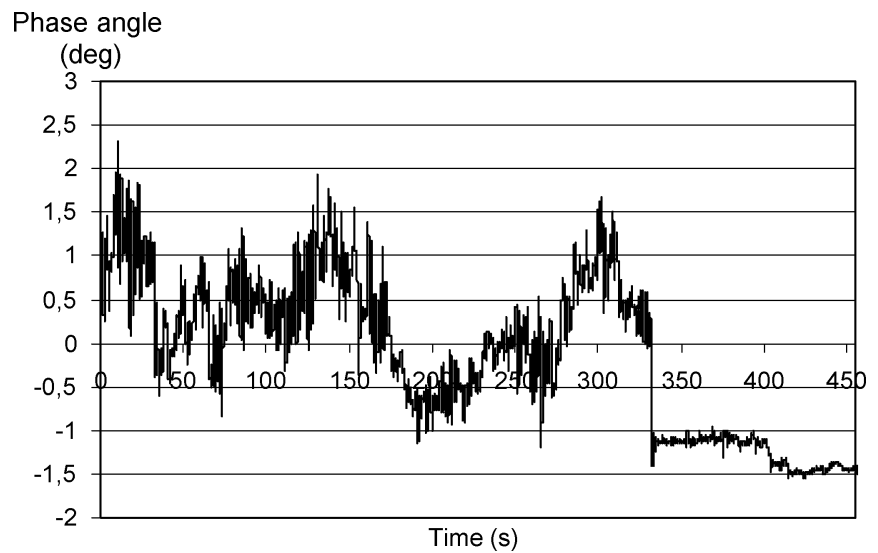

Fig. 6. Voltage phase angle difference between SAN and ASV busbars measured as a function of time.

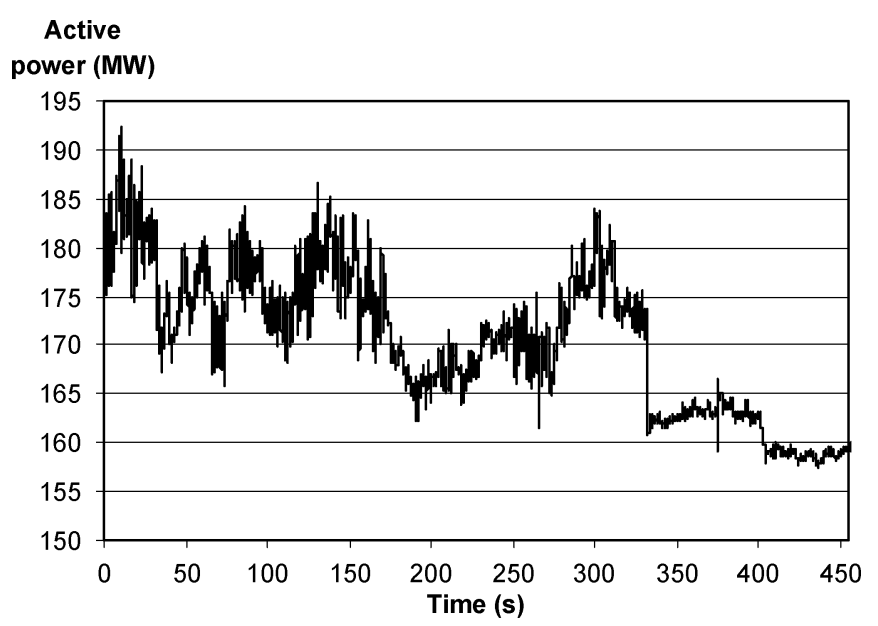

Fig. 7. Active power flow in the $132-\mathrm{kV}$ interconnection measured at MRP as a function of time.

case nor generalized for a number of sudden disturbances or outages.

Fig. 7 shows that prior to the $400-\mathrm{kV}$ tie-line connection power swings were excited between the systems interconnected via a double $132-\mathrm{kV}$ line only. The relative change in phase angle between SAN and ASV during the tie-line outage affected power oscillations, which were superimposed on the steady-state line flow in the power system [1]. The correlation between the change in tie-line power flow (see Fig. 7) and difference in voltage phase angles (see Fig. 6) is obvious, which is evidently described by (1). The active power flow in the $132-\mathrm{kV}$ interconnection was reduced by $10 \mathrm{MW}$ immediately after the double $400-\mathrm{kV}$ tie-line was taken into operation. It is observed that the power swings were damped sufficiently, and finally, the system was settled down to equilibrium.

A harmonic analysis of the active power flow on the $132-\mathrm{kV}$ tie-line after the switching event $(t>330 \mathrm{~s})$ was performed using the discrete Fourier transform (DFT) function in the Matlab Signal Processing Toolbox. The horizontal axis shown in Fig. 8 is related to a frequency scale up to $6 \mathrm{~Hz}$, while the vertical axis is related to the magnitude (complex modulus) of the DFT transformation of the power flow measurement. Interarea oscillation modes of the Nordic system are identified in the low-frequency range $(0.1-1.0 \mathrm{~Hz})$ of Fig. 8 . The largest peak reveals a dominant eigenfrequency of about $0.7 \mathrm{~Hz}$, which

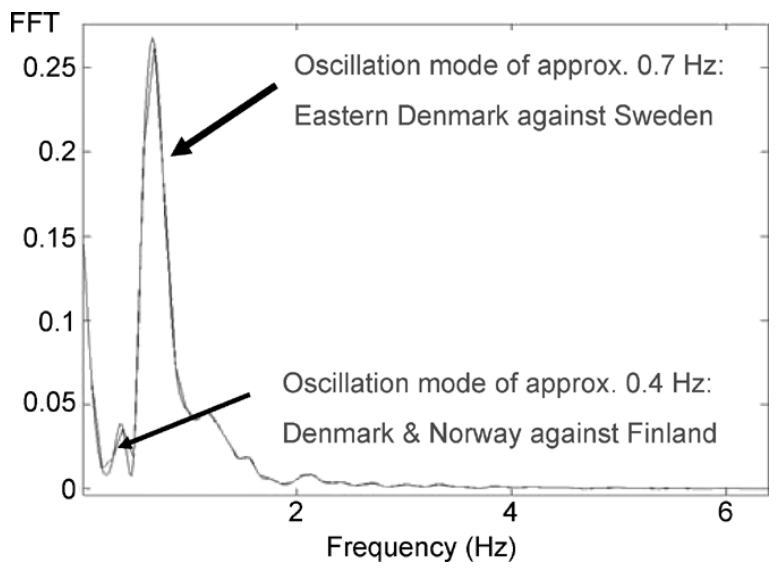

Fig. 8. Spectral analysis of $132-\mathrm{kV}$ tie-line flow.

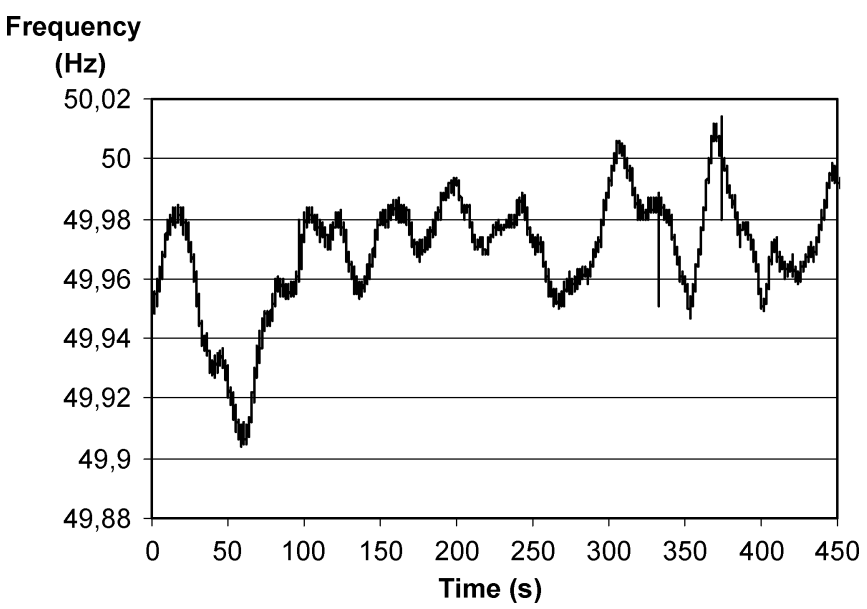

Fig. 9. Frequency measured at SAN substation.

corresponds to the oscillation mode between Sweden and Eastern Denmark [9].

A less distinct peak is evident at a frequency of about 0.4 $\mathrm{Hz}$, which is related to an oscillation mode involving all the generators in the Nordic system. In this case, the system inertias swing into two generators groups, where Denmark and Norway swing against Finland [14].

The measured frequency variation at SAN substation is given in Fig. 9. The rapid frequency transients at 330 and $370 \mathrm{~s}$ are caused by reconnection of the first and the second $400-\mathrm{kV}$ line at SAN, where the frequency is also recorded. The graph of the respective frequency at ASV is not depicted, as it follows the same trend as SAN due to the strong $400-\mathrm{kV}$ connection between ASV and SAN measuring locations.

\section{Simulations}

The objective of the simulation analysis in the Power System Simulator for Engineering (PSS/E) ${ }^{3}$ program was to reproduce the behavior of the Eastern Danish transmission system during the reconnection of the double $400-\mathrm{kV}$ tie-line. Static and dynamic simulation of the reconnection sequence was performed using a detailed power system model for Eastern Denmark with a simplified representation of the Swedish grid equivalent (see Fig. 3). To make the reference load flow case as exact as

\footnotetext{
${ }^{3}$ From Power Technologies, Inc. (PTI).
} 
possible, the initial conditions for the 400- and 132-kV power system are based on actual data for generation dispatch and transfers to Sweden and zero transfer to Germany, which are captured by a limited amount of Supervisory Control And Data Acquisition System (SCADA) 4 system data, which reveals the operating condition for the particular hour of the day in the control center at the ISO of Eastern Denmark.

During the actual situation, the power system was not severely stressed as the tie-line transfer was low, and the total system load was about $65 \%$ of the maximum winter load. In the simulation model, substation SAN is connected to a simple Swedish generation equivalent, which is accounted as a slack bus with zero phase angle. An estimate for the local load at the Swedish side (MEQ) is represented by load equivalent of $120 \mathrm{MW}$ connected at MRP busbar. In the reference load flow case, the line HVE-SAN is disconnected and about $52 \mathrm{MW}$ are sent from Sweden to Eastern Denmark via the 132-kV tie-line MRP-TEG. The power transfer with Sweden is rather low compared to the transfer limit in normal operation, because it is set intentionally as a precaution measure against widespread disturbance.

This initial condition is characterized by small phase angle change (about $0.5^{\circ}$ ) between ASV and SAN substations. The small initial angles are indeed indicative of a strong and lightly loaded system. The power plant at ASV delivers about $244 \mathrm{MW}$ via the $400-\mathrm{kV}$ lines. After the reconnection of the $400-\mathrm{kV}$ tieline, the steady-state phase angle difference between ASV and SAN is slightly changed to about $1.3^{\circ}$, and about $10 \mathrm{MW}$ are transmitted via the 400-kV tie-line HVE-SAN. The active power toward 132-kV busbar MRP (see Fig. 3) was reduced by the same amount of power. In the intact network, the active power from MRP provides the local load equivalent at MEQ, and the remaining $40 \mathrm{MW}$ are directed to Denmark via the $132-\mathrm{kV}$ tieline MRP-TEG. The simulated power transfer from Sweden (SAN) to Denmark (HVE) complies with the calculated values from (1) for the tie-line flow, taking into account the value for line impedance and the small increment in phase angles.

The dynamic simulation in PSS/E presumes steady-state initial condition prior to the reconnection of the $400-\mathrm{kV}$ tie-lines. Each power plant generator was presented together with a power system stabilizer, a detailed governor model, and an excitation model. Switching shunts and voltage control at specified points in the 400- and $132-\mathrm{kV}$ transmission network were considered in the simulations.

The voltage magnitude at SAN was simulated during a 100 -s period, under the assumption that each $400-\mathrm{kV}$ tie-line is re-energized simultaneously at both ends. Actually, the circuit breakers were not closed simultaneously, and four switching events can be spotted in the PMU recordings. Thus, the previous assumption does not reveal the exact power system operation. Starting from a $413-\mathrm{kV}$ initial value, the voltage at SAN increases in steps after reconnecting the first line (330 s) and the second 400-kV tie-line (400 s) (see Fig. 10). When the SAN voltage is stabilized, it attains a final value of $415 \mathrm{kV}$, which corresponds exactly to the average measured value for the intact network shown in Fig. 5. Analogous to the measured curve in Fig. 6, the calculated difference in voltage angles between SAN

\footnotetext{
${ }^{4}$ The SCADA system at the Operational Control Center [independent system operator (ISO) Elkraft System] collects data every 5-10 s. The data are typically averaged to values valid for the hour in question.
}

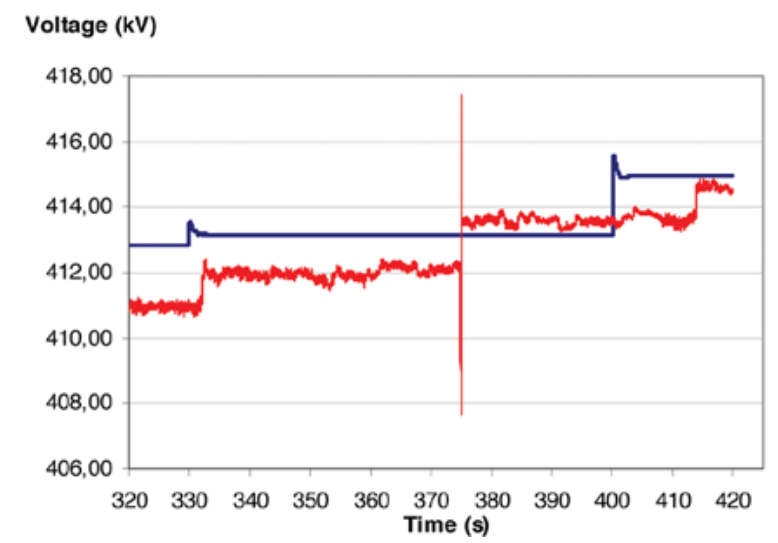

Fig. 10. Simulated versus measured voltage magnitude at SAN as a function of time.

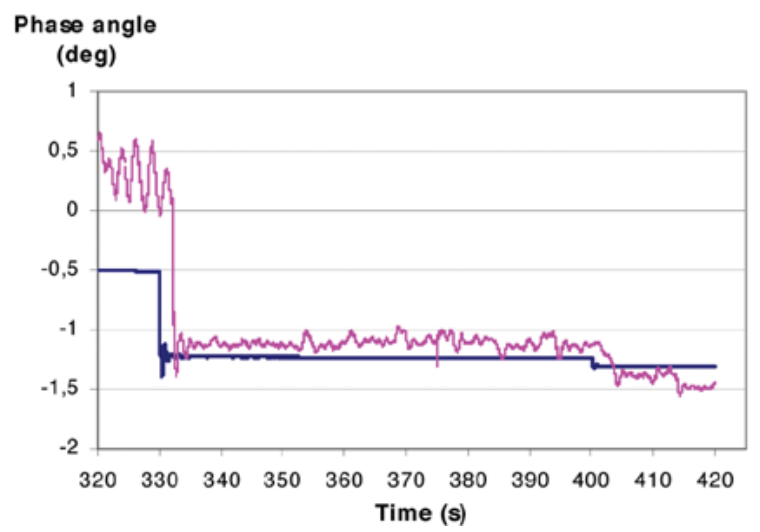

Fig. 11. Simulated versus measured voltage phase angle difference between SAN and ASV busbars as a function of the time.

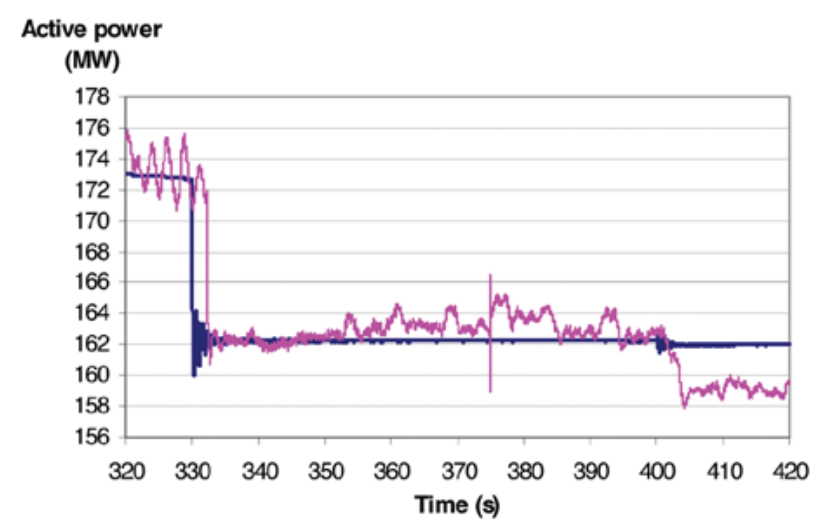

Fig. 12. Simulated versus measured active power flow in $132-\mathrm{kV}$ tie-lines to MRP transformer station.

and ASV is illustrated in Fig. 11. A characteristic shift of about $-0.9^{\circ}$ is recorded immediately after the simulated reconnection of the first line $(330 \mathrm{~s})$, while the subsequent line connection $(400 \mathrm{~s})$ results in a minor shift in the relative phase angle.

The simulated post-disturbance value of relative voltage phase angle after $400 \mathrm{~s}$ is relatively close to the corresponding measured quantity. Fig. 11 reveals a discrepancy of some $0.75^{\circ}$ during the period 320-330 s. This initial difference is caused by inexact representation of the $132 \mathrm{kV}$ for the Swedish network equivalent and the uncertainty of the particular load condition. The measured oscillatory behavior in phase angle (see Fig. 11) and power flow (see Fig. 12) prior to the switching event arises 
from internal impacts from Swedish generators. A complete match between the simulated and the monitored system conditions is a difficult task due to discrepancies between the pre-fault load flow in the simulation and the actual conditions prevailing in the power system recorded by instantaneous phasor data from the PMU units.

The main reason is the fact that the initial load flow condition was based on SCADA recordings reported as averaged values in the particular hour interest. Furthermore, the system loads were not exactly known at the time the phasor measurements were realized.

The recorded active power oscillations prior to the switching event are not considered critical, since they are damped successfully in the intact network. This discrepancy results from the assumption that the dynamic simulation starts from steady-state initial conditions, which do not coincide with the real measurements [6]. This is due to the fact that the exact operating situation in the entire power system is not precisely known. On the other hand, the simulated power flow in the $132-\mathrm{kV}$ tie-line (see Fig. 12) is in good agreement with the actual measured power flow during the reconnection sequence. The simulated post-disturbance value of $162 \mathrm{MW}$ is about $2 \mathrm{MW}$ higher than the corresponding value measured as average in the intact network. The simulated active flow at $330 \mathrm{~s}$ is about $13 \mathrm{MW}$ less than the initial value of $173 \mathrm{MW}$, which is in good correspondence with the shift observed at the corresponding point in the measured curve.

\section{CONCLUSION}

This paper presents one of the first Nordic applications of synchronized phasor measurements in monitoring power system oscillations during a tie-line switching. Two ABB RES 521 PMU $\beta$ prototypes provided simultaneous recordings of voltage and current phasors at key buses. The measured tie-line power flow and dynamics in the voltage phase angles revealed low-frequency oscillations of a group of machines within a large area (Sweden) against the neighboring area (Eastern Denmark) in the Nordic system. The PMU data were a valuable tool in post-disturbance analysis of the dynamic behavior of the Eastern Danish power system with respect to the Swedish interconnection during the $400-\mathrm{kV}$ tie-line switching. The presented recordings justify the high accuracy and feasibility associated with synchronized phasors. The phase angle accuracy is related to relatively small errors introduced by transducers. The synchronization using GPS has high precision, since the samples are time tagged with an accuracy of $1 \mu \mathrm{s}$.

This paper demonstrates that direct observation of interarea oscillation modes using phasor measurements is more convenient than computation of eigenvalues using a detailed model of a specific system configuration. The recorded power system response is to some extent consistent with the dynamic simulation results. The initial condition assumptions as well as the imprecise model for the Swedish equivalent can explain the discrepancy between the simulated curves and the phasor recordings prior to the reconnection of the $400-\mathrm{kV}$ tie-line.
The limited availability of detailed small signal stability models of the Nordic system demanded the simulation with a simplified Swedish power system model, which was shown to be insufficient for correct simulation of power oscillations and precise determination of eigenvalues. The application of synchronized phasor measurements for, e.g., validation of power system models used in stability studies, is seen as having great potential in the future. Future perspective of real-time phasor data is seen in developing tools for detecting and preventing dynamic problems rather than simply analyzing critical power system events.

\section{ACKNOWLEDGMENT}

The authors would like to thank ABB for its contributions, which made it possible to borrow prototypes of PMU.

\section{REFERENCES}

[1] P. Kundur, Power System Stability and Control. New York: McGrawHill, 1993.

[2] P. M. Anderson and A. A. Fouad, Power System Control and Stability. Ames, IA: Iowa State Univ. Press, 1977, vol. I.

[3] G. T. Heydt, C. C. Liu, A. G. Phadke, and V. Vittal, "Solutions for the crisis in electric power supply," IEEE Comput. Appl. Power, vol. 14, no. 3, pp. 22-30, Jul. 2001.

[4] A. G. Phadke, "Synchronized phasor measurement in power systems," IEEE Comput. Appl. Power, vol. 6, no. 2, pp. 10-15, Apr. 1993.

[5] K. E. Martin, "Phasor measurements at the Bonneville power administration," in Proc. Power Systems Communication Systems Infrastructures Future, Beijing, China, Sep. 2002.

[6] R. O. Burnett, M. M. Butts, T. W. Cease, V. Centeno, G. Michel, R. J. Murphy, and A. G. Phadke, "Synchronized phasor measurements of a power system event," IEEE Trans. Power Syst., vol. 9, no. 3, pp. 1643-1650, Aug. 1994.

[7] A. G. Phadke and J. S. Thorp, Computer Relaying for Power Systems. New York: Wiley, 1988.

[8] M. Hemmingsson, O. Samuelsson, K. O. H. Pedersen, and A. H. Nielsen, "Estimation of electro-mechanical mode parameters using frequency measurements," in Proc. IEEE Power Engineering Society Winter Meeting, vol. 3, 2001, pp. 1172-1177.

[9] A. H. Nielsen, K. O. H. Pedersen, and O. Samuelsson, "An experimental GPS-based measurement unit," in Proc. Nordic Baltic Workshop Power Systems. Tampere, Finland, Feb. 4-5, 2002.

[10] O. Samuelsson, "Wide Area Measurements of Power System Dynamics-the North American WAMS Project and Its Applicability to the Nordic Countries," ELFORSK, 99:50, Jan. 2000.

[11] System protection schemes in power networks, in Electra, no. 196, pp. 50-61, Jun. 2001.

[12] M. Hemmingson, "Power system oscillations, detection estimation and control," Ph.D. dissertation, Dept. Ind. Elect. Eng. Autom., Lund Inst. Technol., Lund Univ., Sweden, Mar. 2003.

[13] T. Lysfjord, L. Messing, B. Ingemars, T. Keränen, and T. Østrup, "Improved Damping of Power Oscillations in the Nordic Grid Using Optimization of Adjustable Control Parameters for Power System Stabilisers," (in Swedish: Förbättrad dämpning av effektpendlingar i nordelnättet genom optimering av inställbara reglerparametrar för dämptillsatser), Nordel, 1982-06-15.

[14] K. Uhlen, S. Elenius, I. Norheim, J. Jyrinsalo, J. Elovaara, and E. Lakervi, "Application of linear analysis for stability improvements in the Nordic power transmission system," in Proc. IEEE Power Engineering Society General Meeting, Toronto, ON, Canada, Jul. 13-17, 2003.

[15] J. Ballance, B. Bhargava, G. D. Rodriguez, and Southern California Edison, "Use of Synchronized Phasor Measurement System for Enhancing AC-DC Power System Transmission Reliability and Capability,", CIGRE Session C1-210, 2004.

[16] B. Eliasson, "Damping of power oscillations in large power systems," Ph.D. dissertation, Dept. Autom. Control, Lund Inst.Technol., 1990. 


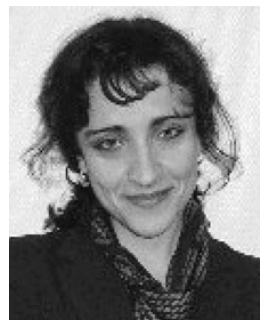

Joana Rasmussen was born in Skopje, Macedonia, in 1971. She received the B.Sc. degree from the Faculty of Electrical Engineering, Macedonia, in 1996 and the M.Sc. degree from the Technical University of Denmark, Lyngby, Denmark, in 1999. She is working toward the Ph.D. degree from the Technical University of Denmark. Her Ph.D. project is carried out in close cooperation with Elkraft System, Ballerup, Denmark, which is the ISO for Eastern Denmark.

Her industrial experience includes being a Development Engineer with the Research Institute of Danish Electrical Utilities.

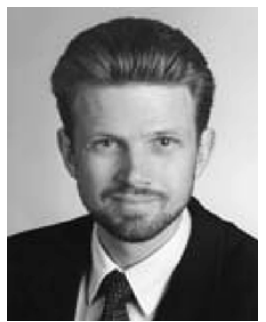

Preben Jørgensen (SM'00) was born in Denmark in 1958. He received the M.Sc. degree in electrical engineering and the Ph.D. degree from the Technical University of Denmark, Lyngby, Denmark, in 1987 and 1990, respectively. He received a Graduate Diploma in business administration (organization and management) from the Copenhagen Business School in 2000 .

He was with Elkraft Power Company Ltd., Ballerup, Denmark, from 1990 to 1994. From 1994 to 2000 , he was with the Research Institute of Danish Electrical Utilities and the Head of the Department of Electrical Distribution Technology for the last five years. Since 2000, he has been the Director of the Transmission Department at Elkraft System Ltd. Among other things, he has been working with probabilistic production simulations, capacity expansion planning, power quality, electric measuring, superconductivity, electric power distribution, transmission, management, and HRM. 